\title{
A STUDY OF CLINICAL PERFORMANCE OF NURSES WHO RECENTLY COMPLETED THE COMPREHENSIVE BASIC NURSING COURSE
}

\author{
BB Ntombela, ND Mzimela, CS Mhlongo and TG Mashaba
}

\begin{abstract}
A study was conducted to assess clinical performance of registered nurses who had recently completed the new comprehensive basic nursing course. This regional project was undertaken because of controversy surrounding clinical competence of the graduates/diplomates of the new regulation course. Senior qualified nurses gave their views according to Likert Scale statements and open-ended questions. Findings were that the sample was of the opinion that clinical performance of the new graduates/diplomates falls short of expectations.
\end{abstract}

\section{INTRODUCTION}

In this study an attempt was made to assess the clinical performance of graduates and diplomates of the recently introduced Basic Nursing Course and to establish if the course prepared them adequately. The course prepares candidates for rendering a service as professional nurses in the general, psychiatric and community health fields as well as in the capacity of midwife. It is a four year course offered as from 1986 by Universities as a degree and by Colleges as a Diploma nursing course.

\section{ORIENTATION}

In 1985 the South African Nursing Council passed regulations providing for introduction of the four year course at all nurse training institutions. Such a course would prepare student nurses for registration with the South African Nursing Council (S.A.N.C.) as a nurse (general, psychiatric, community health) and midwife. In this study, this course will be referred to subsequently as the "new regulation" course. It replaced and was an improvement on the previous Basic Nursing Courses (hereafter referred to as the "Old regulation" course) whereby a candidate could take up to a minimum of seven years to acquire the same four basic nursing qualifications.
The latter course made for thorough grounding in practical nursing skills of each nursing speciality but proved to be expensive in the long run, time consuming and involved overlapping and duplication of subject matter. The new course is integrated so as to ensure relatively faster production of nurse practitioners who are competent in the four nursing specialities. It also was streamlined to fit into the tertiary education system of the country and to be in line with similar developments in countries like the United Kingdom and Australia.

\section{PROBLEM STATEMENT}

It is estimated that the first graduates and diplomates of the new regulation course started practising as qualified nurses as from 1990. When this Basic Course was introduced there were differences of opinion among registered nurses as to whether such a course would be effective in producing competent nurse practitioners in view of its diminished clinical learning experience. This is illustrated by, among others, Armstrong (1987) referring to this course as an "unwanted pregnancy". As the newly qualified nurses take up employment the controversy continues at grassroots level. There are nurses who have reservations about the quality of nursing care rendered by the newly qualified nurses. Against the background of the SANC scope of practice of the registered nurse and of the terminal course objectives of the new regulation course set by some institutions, the question being asked is :"Do the newly qualified nurses really fall short of expectations in their clinical performance?"

If the negative allegations can be proved to be false then it is time the "ghost" of poor quality care by these graduates/diplomates is laid to rest.

\section{OBJECTIVES OF THE STUDY}

The goal of this investigation was to ascertain the extent to which products of the new regulation basic course meet expected competence in clinical nursing practice wherever they are employed. Specific objectives were to:-

- assess the level of clinical competence of graduates/diplomates of the new regulation basic course
- identify problems experienced by clinical personnel in working with these graduates/diplomates

- identify strengths in clinical performance of the new regulation course products

\section{ASSUMPTIONS UNDERLYING THE STUDY}

This investigation was based on the assumption that:-

- one of the best sources of information would be the opinions of senior or older nursing personnel working closely with the graduates/diplomates of the new regulation course

- the senior/older nurses are familiar enough with the objectives of the new regulation course to make a realistic assessment of the quality of its products.

\section{LITERATLRE REVIEW}

\section{The Historical Background}

Historically the major problem in nursing world wide is how to provide nursing services in the quantity demanded and quality needed (Creelman, 1969). Quality nursing practice depends upon quality nursing education.

As far back as 1952, the World Health Organisation (WHO) working conference on nursing education suggested that the basic need in most countries and especially in developing countries, was for nurses capable of providing total nursing care both in hospital or home and who could integrate preventive and curative services in any setting (Mooneyhan, 1979). Then came the time when emphasis was placed on professional nurses functioning in an expanded or extended role not withstanding that not all nurses had been prepared formally for such functions.

As an attempt to hasten production of nurses who could function in more than one speciality, in the 1970s the SANC passed regulations for combined courses such as:-

- General nursing and midwifery

- General nursing and psychiatry. 
Even in those days older members of the nursing profession had reservations about the clinical competence of nurses educated and trained through these combined courses (Mashaba, 1985). In 1985 the SANC passed regulations providing for the institution of the comprehensive course combining the four nursing specialities (South African Nursing Council R425, 1985).

The new four year basic course was introduced for the first time in 1986 by all Colleges of Nursing and Universities and the first graduates and diplomates of this course took up employment in 1990. The undercurrent of uneasiness about clinical competence of this new generation of nurses led to the undertaking of this study of the assessment of clinical performance of graduates/diplomates of the new basic course.

\section{DEFINITION OF TERMS}

Assessment means measurement of an ability to carry out a specified task. It is a generalisation made on the basis of an observation of events (Katz and Snow, 1980; Freeman and Byme, 1976; Girot, 1993).

Performance focuses on the total behaviour of a health worker or the whole range of knowledge, skills and attitudes acquired through training as well as their organisation and integration in practice (Ziv, Ehrenfeld, Kurtzman and Hadani, 1990). In this project performance assessment must be understood to carry the above-stated meaning, that is measurement of the nurses' ability to behave so as to demonstrate knowledge, skills and attitudes acquired through education and training. Assessment will be used interchangeably with evaluation and appraisal.

\section{SIMILAR STUDIES}

Assessing student performance after graduation is an important aspect of programme evaluation (Howard, Hubelbank and Moore, 1989). Urden (1989) recommends on-going evaluation at various levels or stages of career development. The first level is soon after graduation on initial clinical placement, when performance should be marginally acceptable. Then comes the level where the graduate has had 2-3 years of clinical experience, at which the graduate should be competent. After 3-5 years experience another evaluation should be done, in which the practitioner should be proficient.

End of the course assessment at which examiners decide to pass or fail the student is good, but according to de Jager (1990) it shows performance only in respect of specific occasions, and it bears little resemblance to the practitioner's performance on daily activities. The initial clinical exposure of a newly employed new graduate is period of adjustment and adaptation (Speedling, Ahmadi and Kuhn-Weissman, 1981).
Research studies on evaluation of clinical performance in relation to the recently completed course of study include those by Bassett (1993); Freeman and Byrne (1976); Howard et al (1989); Brasler (1993); Katz and Snow (1980); Corner and Wilson-Barnett (1992); Olsson and Gullberg (1987) and Girot (1993).

\section{APPROACHES TO PERFORMANCE ASSESSMENT}

According to literature various approaches have been used. Self-evaluation by the group being studied was used by Speedling et al (1981); Ehrenfeld, Ziv and Bergman (1993); Deane and Campbell (1985); Olsson and Gullberg (1987) and Pierce (1991). An approach which used views of experienced qualified sisters about new graduates performances was employed by Girot (1993); Ziv et al (1990) and Brasler (1993).

The foregoing shows that performance evaluation of newly qualified nurses is a contemporary issue. Post-graduate performance appraisal is necessary to establish whether or not the nurses are dependable, appropriately educated, ready to respond to patients' demand for nursing and to emergencies (Bassett, 1993).

\section{THEORETICAL FRAMEWORK}

Tyler's model of traditional clinical evaluation which begins with objectives of the educational programme must be challenged (Malek, 1988). This rational paradigm may be substituted or complemented by responsive evaluation based on perceptions of other stake-holders concerned about graduate performance. Responsive evaluation constitutes a natural paradigm. Sarnecky (1990) subscribes to this view and advocates fourth generation evaluation or responsive model, evolved by Guba and Lincoln. In this study the natural paradigm was adopted through seeking opinions of at least one group of stakeholders, ie qualified senior nurses working with the newly qualified nurses.

\section{PERFORMANCE INDICATORS}

Assessment is realistic if the concept to be assessed is operationalised. Narayanasamy (1991) maintains that performance indicators be stipulated to test performance before, during and after acquisition of a nursing degree/diploma.

In operationalising "clinical performance" this concept was reduced to the following constinuent variables:-
- bedside nursing practice
- ward administration
- clinical teaching
- ethical conduct/responsibility

\section{INDICATORS}

Performance indicators reported on a 5-point Likert Scale of never, rarely, sometimes, often and always, were as follows:-

a) Bedside nursing practice indicators:-

- identification of problems

- determining priorities

- dexterity in nursing skills

- evaluating care

- revising care plans

- application of knowledge

- independent practice

- respect of dignity and uniqueness of man

b) Ward administration indicators:-

- anticipate workflow problems

- identify resources

- identify actions to accomplish tasks

- implement appropriate action

- direct activities

- evaluate performance

c) Ethical conduct/responsibility indicators:-

- adhere to regulations, laws and policies

- maintain confidentiality and privacy

- accomplish professional goals

d) Teaching function indicators:-

- sensitivity to need to teach

- skill in imparting knowledge

- effectiveness in teaching

The data collecting instrument focused on the above-mentioned indicators in respect of each variable.

\section{COLLECTION OF DATA}

The setring was the province or region in which the researchers were resident. A cross-sectional descriptive survey was used to collect data. The target population was all experienced qualified nurses currently serving in the health service of this province. The convenience sample was employed in that the research tool was distributed to all those qualified nurses who were willing to participate and were accessible to the researcher and those indirectly accessible 
through other colleagues. Qualified nurses who were products of the new regulation course were excluded.

A questionnaire was designed, given to two experts to assess face validity and was pilot tested. Although 200 questionnaires were distributed, only 144 were completed and returned, a return rate of $72 \%$. Out of these, 9 were spoiled so eventually 135 questionnaires were processed.

\section{DATA ANALYSIS}

Analysis of data was manual in respect of open-ended questions and by computer for the rest of the items.

\section{RESPONSES TO LIKERT SCALE ITEMS}

The Likert Scale ratings of never, rarely, sometimes, often and always were given a numerical value of 1 to 5 . The maximum possible score was 100 as 20 statements required response; total scores ranged from 35 to 100 with a mean of 73 . Responses of Group I (respondents above the mean) and of Group II (respondents below the mean) were examined for significant correlations.

Responses under the variable Nursing Practice are reflected in Figures 1 to 3 . It is significant that a rating of "never" was made by a substantial number of respondents in respect of indicators $1(27.7 \%), 2(17,8 \%), 7(33,3 \%)$ and $8(20 \%)$. By comparison indicator 5 "revising care plans..." appears to be practised better than other activities in view of the fact that $6.7 \%$ rated this as getting done "always"; $24.4 \%$ said this is done "often" and $28.9 \%$ said this is done "sometimes". In summing up the ratings, (Figure 3 ) Nursing practice as a variable appears to be performed "rarely" according to the majority (38\%) of the sample. According to a minority (2\%) the same activities are practised "always". This does
Figure 1

Bargraph showing performance ratings of new nurses in respect of specific indicators 1 to 4 under the variable: Nursing practice

Always $\bigotimes$ Often Sometimes $\$$ Rarely $\otimes$ Never * OF RESPONDENTS PER RATING

KEY TO

INDICATORS:

1. Identification of nursing care problems.

2. Determination of priorities of care.

3. Clinical skills to carry out nurs intervention.

4. Regular evaluation of the effects of nursing care provided.

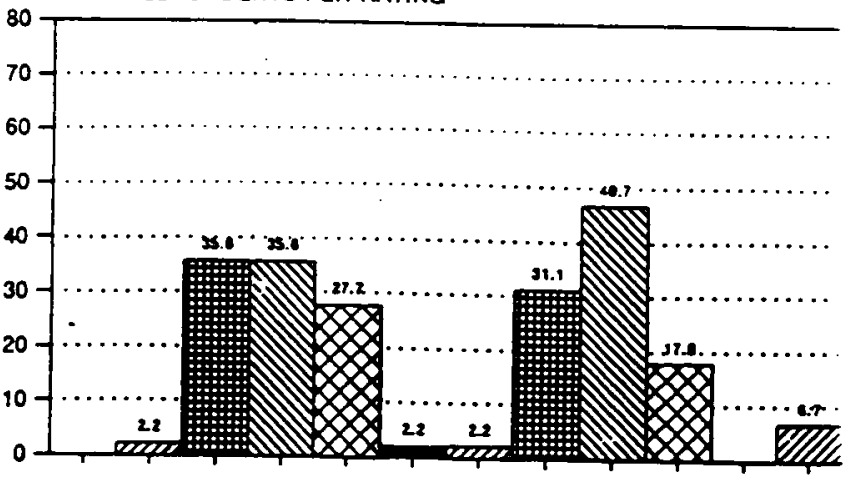

1.

2.

3.

4.

Figure 2

Bargraph showing performance ratings of new nurses in respect of specific indicators 5 to 8 under the variable: Nursing practice

Always ZOthen Sometimes $\$$ Rarely Never

KEY TO INDICATORS:

5. Revision of care plans: utilizing current data.

6. Implementation of knowledge and skills.

7. Ability to practice independently.

8. Respect for the dignity and uniqueness of man. \% OF RESPONDENTS PER RATING

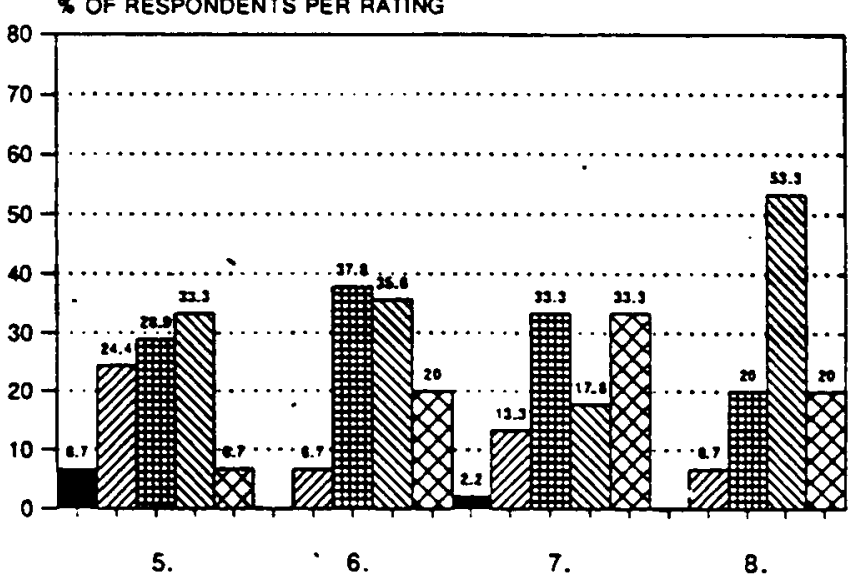

TABLE 1 : RESPONSES TO OPENENDED QUESTIONS:STRONG POINTS

ATTRIBUTE
Freaching of subordinates
Displaying aspects of good
quality nursing
Supervising subordinates
Delegating duties
Allocating duties
Respect for dignity of patients
Application of the nursing process
Displaying loyalty
Teaching patients
Drawing a teaching programme
Doing nursing procedures

Figure 3

Pie diagram showing the overall pertormance rating of new nur ses in respect of the variable: Nursing practice

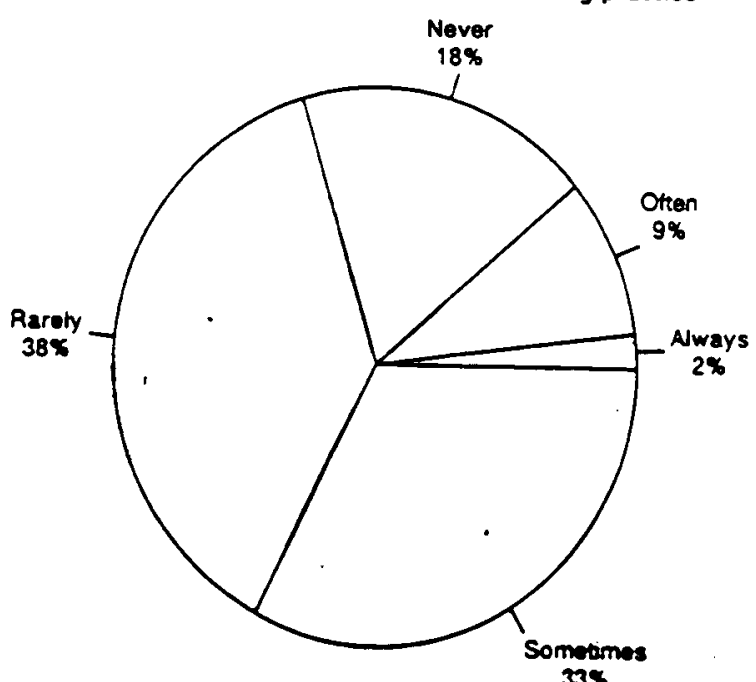




\section{Figure 4}

Bargraph showing performance ratings of new nurses in respect of specific indicators 1 to 5 under variable: Management skills

KEY TO INDICATORS:

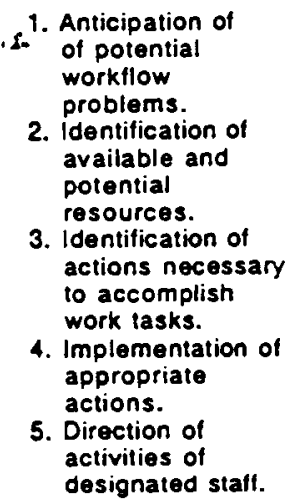

3. Identification of actions necessary to accomplish work lasks.

4. Implementation of appropriate actions.

5. Direction of activities of designated staft.

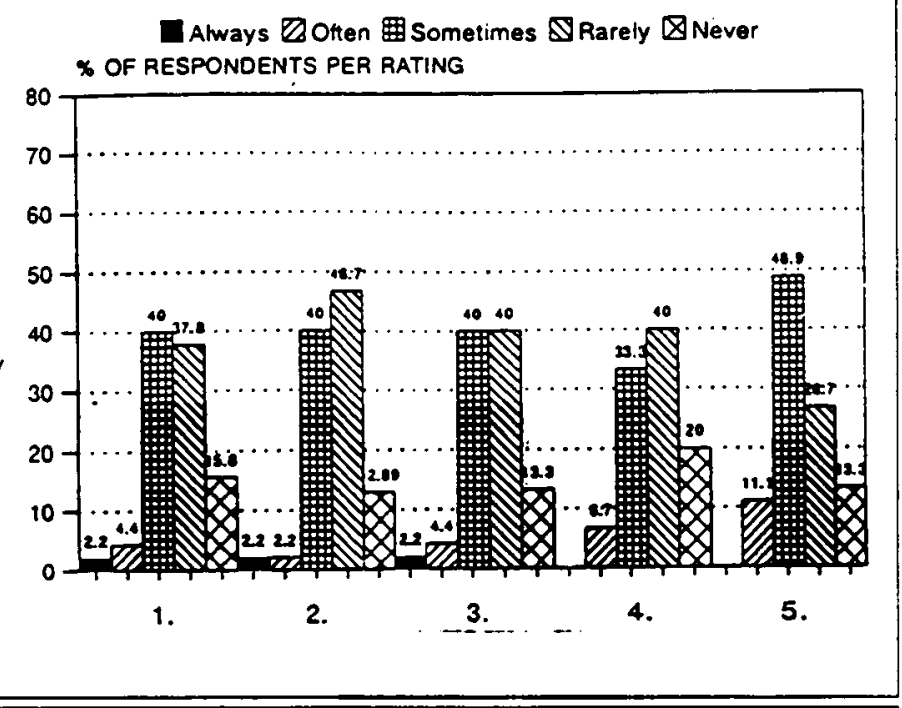

Figure 5

Bargraph showing performance ratings of new nurses in respect of specific indicators 6 to 9 under variable: Management skills

KEY TO INDICATORS:

6 Seeing that work tasks are completed.

7. Evaluation of performance of designated staft.

8. Taking appropriate action to correct unacceptable practices.

9. Contribution to the efficiency of the area/unit.

Always $Q$ Otten 19 Sometimes $\triangle$ Rarely $\otimes$ Never \% of respondents per rating

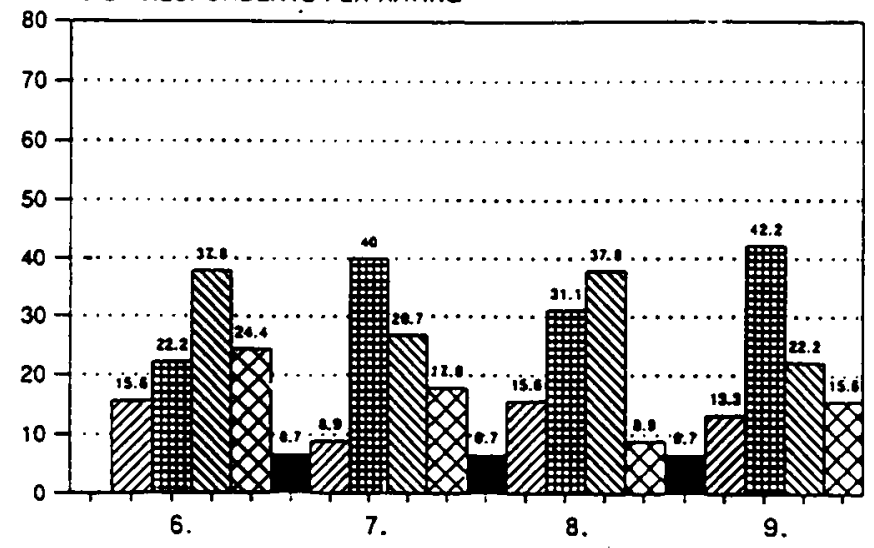

Figure 6

Pie diagram showing the overall performance rating on new nurses in respect of the variable: Management Skills

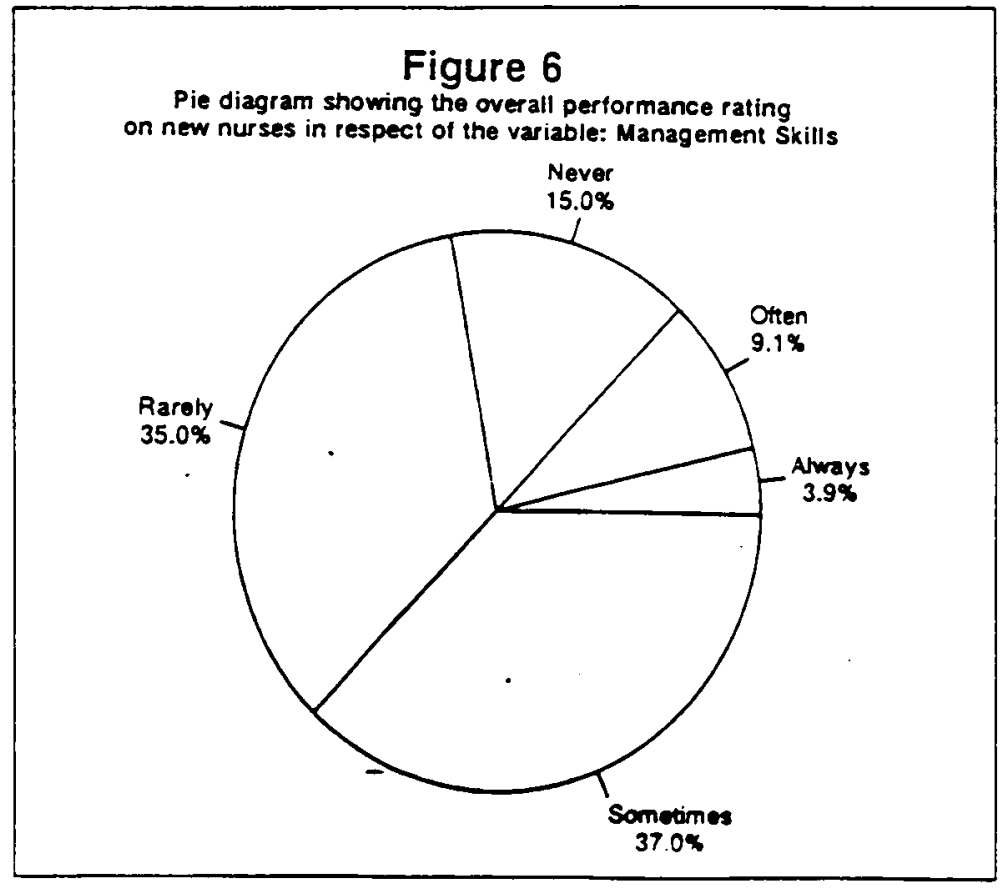

not speak well of the performance of the newly qualified nurses

In correlating responses of Group I and II the Pearson P.M. Correlation co-efficient was found to be significant : $r=942 ; \mathrm{df}=55 ; p(-6)$. In this variable the mean for Group I and II was 34.47 and 23.63 respectively.

Assessing the quality of Management skills or Ward administration as a variable evoked responses shown in Figures 4,5, and 6 . Apparently most management activities/indicators are performed predominantly either "sometimes" or "rarely" by the newly qualified nurses. Doing an activity "always" was non-existent for indicators 4,5 and 6 and was scanty for indicators 1,2 and 3 . It is worth noting that a small portion $(6.7 \%)$ of the sample rated performance of indicators $7:$ "evaluation of performance..", 8 : "appropriate corrective action, and 9 : "contributing to efficiency of the unit" as getting done "always".

The summary of ratings for this variable (Figure 6) was such that the majority (37\%) of the subjects regarded the activities of Management as getting done predominantly "sometimes". Performing of these skills "always" was endorsed by a minority (3.9). This is equivalent to satisfactory performance by the new nurses. In this variable the Pearson P.M. correlation co-efficient between the two groups was significant.

Responses for the variable Responsibility can be seen in Figures 7 and 8 . The rating of "rarely" was made by many respondents in all indicators. A disturbingly high number of subjects $(57.1 \%)$ maintained that indicator 2 : "maintenance of confidentiality" is "never" done by the new nurses. One wonders if this is not concomitant with the general lowering of standards in a society that is getting more permissive. Combined ratings of this variable re-affirm that "rarely" or scanty performance of this aspect is predominant, that is, by $35.6 \%$ of the sample.

\section{TABLE 2 : THEMES OF WEAK POINTS IN THE PERFORMANCE OF NEWLY QUALIFIED NURSES:}

ATTRIBUTES

FREQUENCY

$\%$

Fails to contribute ideas

for improvement

15

Distance themselves in

problem matters

12

Shortage of staft makes it impossible for them to teach

9

Lack initiative and motivation

Do not accept corrections

Do not participate in in-service education
3

3

9

3

3

3 
Another negative signal is that the rating of "always" was made by a negligible number (2.2\%) of the respondents. The Pearson P.M. correlation coefficient between the two groups was $\mathrm{r}=79 ; \mathrm{df}=46 ; \mathrm{p}(-6)$. Means were 13.93 and 9 for Groups I and II respectively.

Lastly, responses for the variable : teaching are illustrated in Figure 9. More than half (51.8\%) of the sample maintained that teaching is done "sometimes" and 5.2\%, (the highest so far) perceive teaching to be done "always". In comparing the performance of this variable with all the previous ones, teaching appears to be done relatively well by the newly qualified nurses.

\section{RESPONSES TO OPEN-ENDED QUESTIONS}

Content analysis of qualitative data yielded themes and categories. A distinction was made between manifest themes (phrases/description) and latent themes and significant meanings. The respondents' remarks amounted to strong points (Table 1) and weak points (Table 2) shown by the newly qualified nurses.

The list of strong points is longer than that of weaknesses. This may suggest that although in the Likert Scale items the new nurses were found to range between weak and satisfactory, the respondents cannot put their finger on the exact trouble spots, which constitutes weaknesses.

\section{DISCUSSION}

Findings of this study show that the qualified experienced nurses in the sample view the performance of newly qualified nurses in a somewhat poor light. It must be borne in mind that the former group of nurses was trained according to the old regulations. The latter group was trained and educated under new regulations and therefore under different circumstances.

The sample indicated that the nursing practice of newly qualified nurses is predominantly poor, though not all of them. This is disturbing. It would be interesting to find out what the patients who are recipients of this service have got to say. Management skills were perceived to range from satisfactory to poor. It is possible that some of the newly qualified nurses regard administrative work as more acceptable than slogging at the bedside of the patient. It is a cause for concem that in respect of responsibility newly qualified nurses' performance was regarded as mainly poor; irresponsible nurses can be a hazard to patients. Apparently these nurses are an asset when it comes to teaching. This function was regarded as ranging from satisfactory to good.

It may be concluded that the products of the new regulation course are not as competent as expected by experienced qualified nurses in the sample. The new nurses' performance has a number of strengths as well as a number of
Figure 7

Bargraph showing performance ratings on new nurses in respect of specific indicators 1103 under the variable: Responsibility

Always $\bigotimes$ Otten Sometimes $\$$ Rarely $\bigotimes$ Never \% OF Respondents PeR Rating

KEY TO

INDICATORS:

1. Adherence to regulations, laws, policies and procedures.

2. Maintenance of confidentiality.

3. Establishment of professional goals.

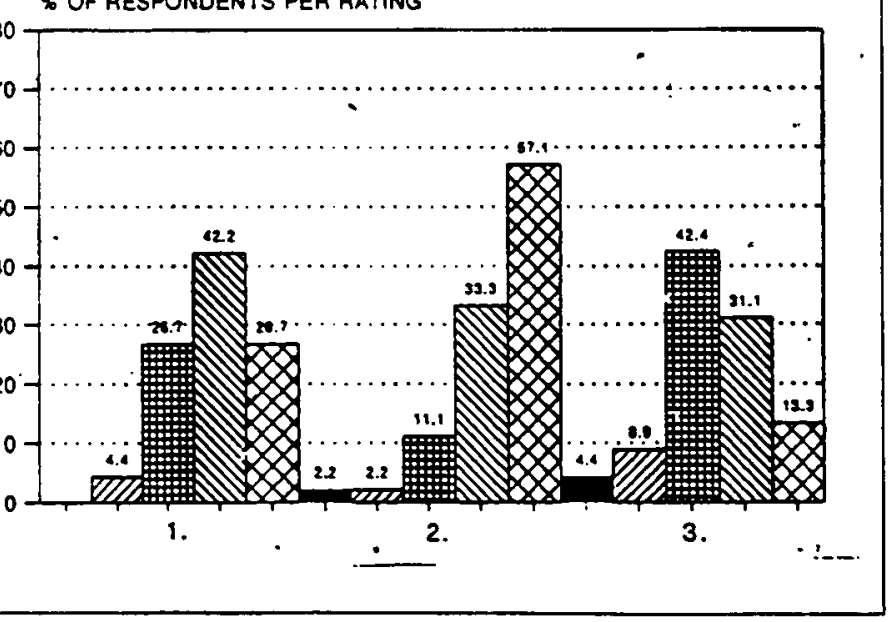

Figure 8

Pie diagram showing the overall performance rating of new nurses in respect of the variable: Responsibility

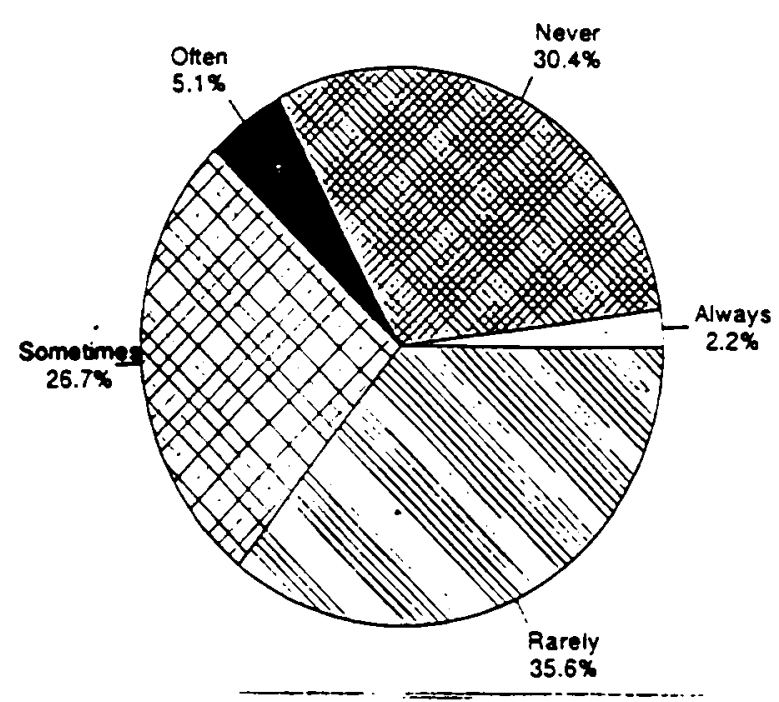

Figure 9

Pie diagram showing the overal performance rating of new nurses in respect of the variable: Teaching

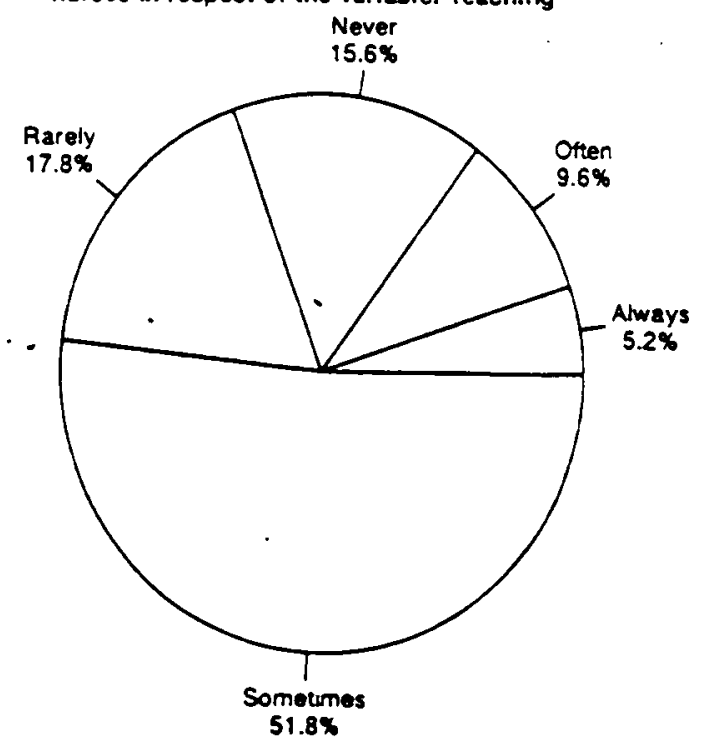


weaknesses which gives problems to the older clinical staff. Collectively, the quality of their clinical performance ranges from satisfactory through poor to never or not at all, with teaching being relatively the best area and responsibility being relatively the poorest area.

In drawing this conclusion it must be borne in mind that the new regulation course is broad, comprehensive and includes four nursing specialities, accomplished within a relatively short span of 4 years. Nursing is as wide as the whole range of human experience. It is not possible in the classroom to teach every contingency obtained in the clinical situation. Therefore, at the end of their course, these candidates are expected to be minimally competent.

The views and opinions of the older qualified nurse cannot be dismissed or taken lightly. However, on the other hand Speedling et al (1981) says the initial clinical exposure of a newly hired, new graduate is a period of adjustment and adaptation. Urden (1989) maintains that there are various levels of career development. The first level is the initial clinical placement where the performance should be marginally acceptable; then after three years of clinical experience the graduate should be competent; after five years the practitioner should be proficient. Further, Bassett (1993) observes that there may be a shortcoming in the performance of new nurses due to the reduction in the time spent with patients during the formative months of training. This writer says further that senior or older nurses view the young nurses in the light of values possessed by themselves. Bassett (1993) therefore is implying that in accepting responses of senior nurses about new nurses' quality of work, room should be made for conservative tendencies, ingrained notions and general resistance to change.

\section{RECOMMENDATIONS}

Due to the limited size of the sample, these findings cannot be generalised to the rest of the target population. Nevertheless this study serves as a preliminary step and lays a foundation for further studies. It is significant in that it sounds a waming along the lines indicated by de Jager (1990). This writer points out that end of the course examination is not a perfect indicator of the ability of the nurse to function effectively in an everyday nursing situation. That being the case, good examination results and a high pass rate should not make nursing school authorities comfortable and complaisant about their graduates. It is therefore, recommended that:-

- support and clinical orientation be routinely and actively provided for newly appointed new nurses for the sake of patients

- on the job performance assessment of graduates and diplomates of the new regulation course be institutionalised.
Nursing school authorities should routinely follow up and assess performance of their graduates in their new jobs, in collaboration with clinical or service authorities

- the nursing profession to seriously consider systematic knowledge and skills development in clinical practice as advocated by Urden (1989). This is a model whereby graduates are evaluated on being employed for the first time for performance that is marginally acceptable. About three years later, in a similar setting they are evaluated for competent performance and five years later, for proficient performance

- older nurses be oriented to judge clinical performance of nurses of the new regulation in a realistic and objective manner.

\section{REFERENCES}

Ahmadi, $K_{n}$ RNs to the world of the medical centre

Kuhn-Weissman, G.International Journal of Nursing studies, 18, 4, 217

Armstrong, SJ. (1987): Unwanted pregnancy Nursing RSA. 1,(11) 18-20.

Bassett, C.C. (1993): Socialisation of student nurses into the qualified nurse role. British Journal of Nursing, 2,(3),179-182.

Brasler, M.E. (1993): Predictors of clinical performance. Journal of continuing education in nursing.

Corner, J. Wilson-Barnett, J. (1992): The newly registered nurse and the cancer patient : An educational evaluation. Journal of International studies, 29,(2), 177-190.

Creelman, L. (1969): Quality care in the right quantity : two decades of WHO nursing assistance. WHO Chronicle, 23, 171

Deane, D. (1985): Developing professional effectiveness in CAMPBELL, J.nursing. Virginia : Reston Publishing Company.

De Jager, L.E. (1990): More on assessment Nursing RSA, 5,(10), 21-23.

Ehrenfeld, M. (1993): Follow-up of RN-BA graduates of Tel Aviv

Finn, B. 188. Katz, F.M. (1980): Assessing health workers' performance. SNOW, $R$ A manual for training and supervision. Geneva, WHO.

Freeman, J. Byrne P.S. (1976): The assessment of post-graduate training in general practice. Surry. Society for research into higher education.

Girot, E.A. (1993): Assessment of competence in clinical practice. Joumal of Advanced Nursing 18.(1). 114-119.

Gullberg, M.T. acquisition. Nurse Education Today, Vol 7, No 6, 270-277.

Howard, E., Hubelbank, J., Moore, P. (1989): Employer evaluation of graduates. Nurse Educator, 14,(5),38-40

Jones, E.L. (1981): Course evaluation in Post Basic education. Journal of Advanced Nursing. 6. 179-188
Katz, F.M., Snow, R. (1980): Assessing health workers' performance. A manual for training \& supervision. Geneva, WHO.

Kurtzman, C., Hadani, P.E. first seven graduate classes. Journal of Professional Nursing, Vol 6. No 4, 229.

Malek, C.J.(1988): Clinical evaluation challenging tradition. Nurse Educator, 13, 6, 34-37.

Mashaba, T.G. (1985): The history of nursing education for the black nurse in South Africa 1900-1982. Unpublished thesis. Pretoria : University of South Africa.

Mooneyhan, E.(1979): The professional nurse in developing countries - practice and preparation. International Nursing Review, 26,1, 17-20.

Narayanasamy, A. (1991): The application of performance indicators to nurse education Nurse Education Today, 11, 341-346.

Olsson, H.M., Guliberg, M.T. (1987): Nurse Education and professional role acquisition Nurse Education Today. 7, 6, 270-277

Peirce, A.G. (1991): Preceptorial students' view of their clinical experience. Joumal of Nursing Education, 30, 6, 244-249.

Sarnecky, M.T. (1990): Program evaluation. Par 1.4 Generations of theory. Nurse Educator, 15 , 5, 25-28.

South African Nursing Council (1985): R425 Regulations relating to the approval of and the minimum requirements for the education and training of a nurse (general, psychiatric and community) and midwife leading to registration. Pretoria, S.A. Nursing Council.

Speedling, E.J.; (1981): Encountering reality; reactions of newly hired RNs to the world of the medical centre. International Journal of Nursing Studies. 18,4,217

Urden, L.D. (1989): Knowledge development in clinical practice. Journal of continuing education, 20,1, 18

Ziv, L., Bergman, R. University. Intemational Joumal of Nursing Studies, 30,(1), 81-90.

Ziv, L.; Ehrenfeld, M. (1990): Follow-up of Hadassah Nursing School's

BB Ntombela
Lecturer: Department of Nursing,
University of Zululand
DN Mzimela
Lecturer: Department of Nursing,
University of Zululand
CS Mhlongo
Lecturer: Department of Nursing,
University of Zululand
TG Mashaba
Professor \& Head:
Department of Nursing,
University of Zululand

